\title{
Volatilidade e determinantes dos capitais externos: os casos do Brasil e dos EUA*
}

\author{
Volatility and determinants of external capital: the cases of Brazil and the USA
}

Eliene de Sá Farias e Leonardo Bornacki de Mattos ${ }^{* *}$

\begin{abstract}
Resumo: A volatilidade dos capitais externos é um risco para a estabilidade macroeconômica e financeira. Este estudo identifica e analisa os determinantes da volatilidade dos capitais externos, para o Brasil e os Estados Unidos, do primeiro trimestre de 1990 ao segundo trimestre de 2018. Depois de construir duas medidas de volatilidade para os capitais externos, estima-se os determinantes dessa volatilidade por meio do modelo VEC e DOLS. Os resultados sugerem que a volatilidade da entrada de capitais externos é superior para o Brasil, por outro lado, para a saída de capitais domésticos, sobressai-se a volatilidade dos capitais dos EUA. Os principais resultados sustentam que algumas variáveis se destacam como influenciadoras da volatilidade dos capitais externos, quais sejam: o risco global, a inflação e o preço do petróleo. Conclui-se que as políticas ligadas à estabilidade financeira decorrentes de volatilidade de capitais podem se pautar por quais tipos de capitais apresentam efeitos mais danosos em termos de volatilidade.
\end{abstract}

Palavras-chave: Volatilidade. Fluxos de capitais. Integração financeira

\begin{abstract}
The volatility of external capital is a risk to macroeconomic and financial stability. This study identifies and analyzes the determinants of foreign capital volatility for Brazil and the United States from the first quarter of 1990 to the second quarter of 2018. After constructing two volatility measures for foreign capital, the determinants of this volatility are estimated through VEC and DOLS model. The results suggest that the volatility of foreign capital inflows is higher for Brazil, on the other hand, the volatility of domestic capital outflows, stands out in the US. The main results sustain that some variables stand out as influencing the volatility of external capital, namely: global risk, inflation and the price of oil. It can be concluded that financial stability policies resulting to from capital volatility can be guided by which types of capital have the most damaging effects in terms of volatility.
\end{abstract}

Keywords: Volatility. Capital Flows. Financial Integration

JEL Code: F20

\footnotetext{
* Submissão: 31/08/2019. Aprovação: 19/01/2020. DOI: http://dx.doi.org/10.5380/re.v41i76.68880. Os autores agradecem o apoio da FAPEMIG.

** Respectivamente: (1) Doutoranda em Economia Aplicada pelo Programa de Pós-Graduação em Economia Aplicada da Universidade Federal de Viçosa (UFV). E-mail: eliene.farias@ufv.br. ORCID: 0000-0001-9214-3591. (2) Professor Associado no Departamento de Economia Rural da Universidade Federal de Viçosa (UFV) e bolsista de produtividade em pesquisa do CNPq. E-mail: lbmattos@ufv.br . ORCID: 0000-0003-4519-231X.
} 


\section{Introdução}

A circulação dos capitais externos se intensificou a partir dos anos 1990 como consequência do processo de liberalização financeira de um maior número de países. Nesse mesmo período, foi observado alta volatilidade dos capitais externos (ALFARO et al., 2007). A volatilidade dos capitais externos desempenha um papel de preocupação na pauta de políticas. Isso porque os gestores de políticas sofrem desafios quando os países têm ligações externas, logo, há necessidade de trabalhar formas de limitar os riscos da instabilidade financeira $\mathrm{e}$ macroeconômicos (ROCHA; MOREIRA; SILVEIRA, 2017).

A mudança na dinâmica dos capitais externos, sobretudo presença de volatilidade, pode ser usualmente vista em momentos de crises ou de alterações nas expectativas dos agentes. Em momentos de incerteza, o maior receptor de capitais externos é o país emissor da divisa-chave (WEISS; PRATES, 2017). De forma semelhante, os autores afirmam que, em momentos de incerteza, os países em desenvolvimento detentores de moeda periférica são os mais sensíveis às mudanças nas expectativas dos agentes privados globais. A preferência por liquidez por parte dos agentes faz com que os países em desenvolvimento sofram mais fugas de capitais (DOW, 1993).

Entre as economias em desenvolvimento, têm-se o Brasil, o qual aderiu-se à inserção à globalização na década de 1980, com foco na via financeira, de forma que as relações econômicas do país com o resto do mundo foram alcançadas por meio de uma ascendente liberalização financeira mundial (FONSECA; SILVA; ARAUJO, 2017). De 2015 a 2017, a economia brasileira receptou, em média, 3,4\% de investimento direto estrangeiro como proporção do PIB, além disso, os diferenciais dos juros ajudam essa economia a atrair influxos (IMF, 2018). Apesar do seu destaque como receptor de capitais externos na América Latina, no primeiro semestre de 2019, o Brasil saiu da lista dos 25 países que compõem o índice global de confiança para investimentos estrangeiros. Esse fato ilustra a preocupação dos investidores com relação à incerteza política e econômica do país.

Por outro lado, das economias emissoras de divisa-chave, têm-se os Estados Unidos. Os fluxos de capitais dos EUA são relevantes para os mercados financeiros internacionais, dado que o departamento do Tesouro dos EUA informou que os residentes dos EUA possuem US\$ 78,716 bilhões em títulos estrangeiros, e os residentes estrangeiros detêm US\$ 84,422 bilhões em títulos dos 
EUA (CHEUATHONGHUA; PADUNGSAKSAWASDI, 2019). Mais recente, as condições monetárias dos EUA foram consideradas determinantes para o ciclo financeiro mundial ${ }^{1}$, ao ditar "regras" para as condições de financiamento do resto do mundo (REY, 2015).

O interesse do presente estudo não é apenas entender as diferentes dinâmicas de capitais externos para as duas economias, mas buscar respostas da existência da volatilidade e dos períodos mais voláteis, determinantes da volatilidade para entradas de rubricas distintas de capitais e para a saída dos capitais totais. Se os Estados Unidos são capazes de alterar as condições de financiamento como se discute (REY, 2015), buscar diferenças e semelhanças com a volatilidade dos capitais externos e seus determinantes do Brasil, pode auxiliar o desempenho financeiro do Brasil. Como destacado por Cheuathonghua e Padungsaksawasdi (2019), auxiliar os países no entendimento da dinâmica dos fluxos de capitais dos EUA nos mercados financeiros globais possibilitam aos formuladores de políticas locais capacidade de projetar políticas apropriadas para responder aos movimentos dos fluxos de capitais.

O estudo analisa a volatilidade na entrada de capitais totais das três rubricas da conta financeira, quais sejam: investimento direto estrangeiro (IDE), investimento em carteira (IEC) e outros investimentos ${ }^{2}$ (OI). A entrada total de capitais externos é dada pela soma das três rubricas, enquanto que as saídas brutas de capitais, investimento total do ativo, corresponde à soma das categorias de IDE, IEC e OI. Os diferentes fluxos de capitais das diferentes rubricas do capital da conta financeira respondem de forma diferente aos fatores domésticos e externos. $\mathrm{O}$ investimento direto estrangeiro possui abrangência de longo prazo, e parte de razões mais estratégicas (ROCHA; MOREIRA; SILVEIRA, 2017). O investimento em carteira, por outro lado, resulta da exploração de oportunidades de curto prazo, tomando por base a arbitragem entre mercados de capitais nacionais. As rubricas ainda se diferenciam na maturidade, risco, ao emissor, à liquidez e aos demais fatores (ROCHA; MOREIRA; SILVEIRA, 2017). Ainda, as

\footnotetext{
${ }^{1} \mathrm{O}$ ciclo financeiro global engloba as diversas dinâmicas dos fluxos de capitais, tais como booms e quedas. 2 A rubrica "Outros investimentos" corresponde ao somatório líquido dos ativos e passivos referentes a créditos comerciais, empréstimos e financiamentos, moeda e depósito e, também, por ativos e passivos de curto e longo prazo (BACEN, 2002).
} 
ações ou títulos dos IEC podem ser vendidos com mais rapidez e facilidade do que o IDE (SULA; WILLET, 2009).

Uma motivação do presente estudo consiste no fato estilizado sobre a volatilidade de capitais externos. Nomeadamente, a volatilidade da entrada de capitais externos apresenta-se mais volátil em países emergentes (BRONER; RIGOBON, 2005; TESAR; WERNER, 1995; OBSTFELD, 2012; WYPLOSZ, 2001; WEI, 2001; ALBUQUERQUE, 2003; GOLDSTEIN; RAZIN, 2006). Ainda, como sustentado por Broner et al. (2013), há uma diferença em considerar capital líquido e bruto. Para o autor, capital bruto separa por entrada e saída de capitais, enquanto o líquido refere-se à diferença entre eles. A volatilidade dos capitais externos é maior nos capitais brutos comparados aos líquidos (DAVIS; VAN WINCOOP, 2018). Dessa forma, o presente estudo busca avaliar a volatilidade do capital bruto, tanto para a volatilidade da entrada quanto para a volatilidade da saída de capitais externos.

O estudo usa dados trimestrais, abrangendo o primeiro trimestre de 1990 ao segundo trimestre de 2018. A justificativa para esse período engloba a intensificação dos fluxos a partir de 1990, e por esbarrar-se na disponibilidade de dados das séries em tempos atuais. Esse período permite visualizar os efeitos da crise dos subprimes, a qual reforçou a vulnerabilidade das economias emergentes quanto aos fatores globais que afetam a circulação dos capitais externos, e que não estão ao alcance de políticas domésticas. Além disso, esse período de análise acompanha a literatura que se detém na desaceleração dos fluxos de capitais observados desde o ano de 2012 (FMI, 2016), e permite avaliar como se tem comportado a circulação dos capitais externos ao longo do tempo.

O artigo, além desta parte introdutória, está organizado da seguinte forma: a segunda seção discute as formas de determinar a volatilidade na entrada de capitais; a terceira seção apresenta a abordagem metodológica; a quarta delimita os dados e suas fontes; a quinta seção mostra e discute os resultados; e, por fim, a sexta seção conclui.

\section{Formas de determinar a volatilidade dos capitais externos}

Os estudos que investigam a volatilidade dos capitais externos, tema de relevância na pauta de política, são escassos. O estudo de Munhoz e Corrêa (2009) 
usou o modelo ARCH para conjugar as volatilidades médias anuais de cada subconta da conta financeira da economia brasileira de 1995 a 2005. De forma semelhante, Carvalho et al. (2017) utilizou os modelos autorregressivo com heteroscedasticidade condicional ARCH e GARCH para medir a volatilidade na entrada de investimentos estrangeiros no Brasil, no decorrer de 1995 a 2012.

Para o presente estudo, a volatilidade da entrada de capitais, tanto no Brasil quanto nos EUA, é analisada por meio de duas abordagens, a fim de obter estimativas confiáveis, e toma por base estudos como o de Engle e Rangel (2008), Broto, Diaz-Cassou e Erce (2011) e Pagliari e Hannah (2017). Uma das medidas de volatilidade condicional estimada consiste no modelo autorregressivo de heteroscedasticidade condicional generalizado $(\mathrm{GARCH})$, que considera a variância condicional como função de erros passados ao quadrado e de valores defasados da variância condicional. O processo do $\operatorname{GARCH}(1,1)$ analisado pode ser definido da seguinte forma:

$$
\begin{aligned}
& \Delta \text { capitais externos }_{i}=\varepsilon_{i} \sigma_{i} \\
& \sigma_{i}^{2}=\alpha_{0}+\alpha_{1} \Delta \text { capitais externos }_{i(t-1)}^{2}+\alpha_{2} \sigma_{i(t-1)}^{2}
\end{aligned}
$$

Da equação $1, \varepsilon_{i}$ corresponde a um processo de ruído branco gaussiano e $\sigma_{i}^{2}$ é a variância condicional correspondente. Essa medida de volatilidade apresenta algumas desvantagens. As estimativas GARCH, mediante a escassez de dados, pode levar a erros de convergência, sobretudo nos períodos iniciais da amostra. Além disso, as estimativas de probabilidade máxima, no caso de pequenas amostras, podem conter vieses consideráveis. Por fim, alguns casos podem apresentar resíduos sem efeitos ARCH e, com isso, o modelo GARCH se torna inadequado.

Para os Estados Unidos, a presença de volatilidade condicional GARCH $(1,1)$ foi identificada para a entrada de capitais de IEC, ITP e para o total de saída de capitais (ITA). Os montantes de capital externo foram dados como proporção do PIB da economia americana. Os resultados podem ser vistos no APENDICE A.

Para todos os capitais externos que entram (IDE, IEC, ITP) e que saem (ITA) da economia brasileira, foi identificado a presença da volatilidade condicional, considerando esses capitais como proporção do PIB. Os resultados podem ser vistos no APENDICE B. Expressar os fluxos de capitais como proporção do PIB é uma normalização dos valores expressos em moeda para o tamanho das economias (WEISS; PRATES, 2017). 
A segunda forma de medir a volatilidade da entrada de capitais do presente estudo consistiu na identificação de heteroscedasticidade nos resíduos de um modelo ARIMA e corresponde a um avanço da literatura de referência como forma de melhorar a robustez das estimativas resultantes de possíveis erros de especificação.

A segunda medida usada corresponde à variância dos resíduos obtidas por meio da estimação de um ARIMA $(1,1,0)$ nos dados. A escolha das ordens AR e MA adotadas segue a literatura pertinente e, mediante o teste de raiz unitária, as séries usadas são integradas de ordem I (1). Essa medida passa por duas etapas, pois primeiro estimou-se os resíduos do processo AR (1) dado por:

$$
\text { scapitalexterno }_{i}=c+\beta \Delta \text { capitalexterno }_{i(t-1)}+v_{i}
$$

Posteriormente foi realizado um teste para detectar a presença de efeitos ARCH nos resíduos e, no caso em que a hipótese nula de heteroscedasticidada é rejeitada, tem-se que:

$$
\sigma_{i}^{2}=\frac{1}{4} \sum_{j=t-(n-3)}^{t+(n-2)}\left(v_{i}\right)^{2}
$$

O presente estudo usou a medida de volatilidade calculada por meio do ARIMA $(1,1,0)$, sempre que possível, na estimação dos determinantes da volatilidade dos investimentos totais, IDE e IEC. A Figura 1 ilustra a volatilidade produzida pelo ARIMA $(1,1,0)$ dos capitais externos de 1990 a 2018, dados trimestrais. 
Figura 1 - Volatilidade dos capitais externos/PIB (US\$ milhões)
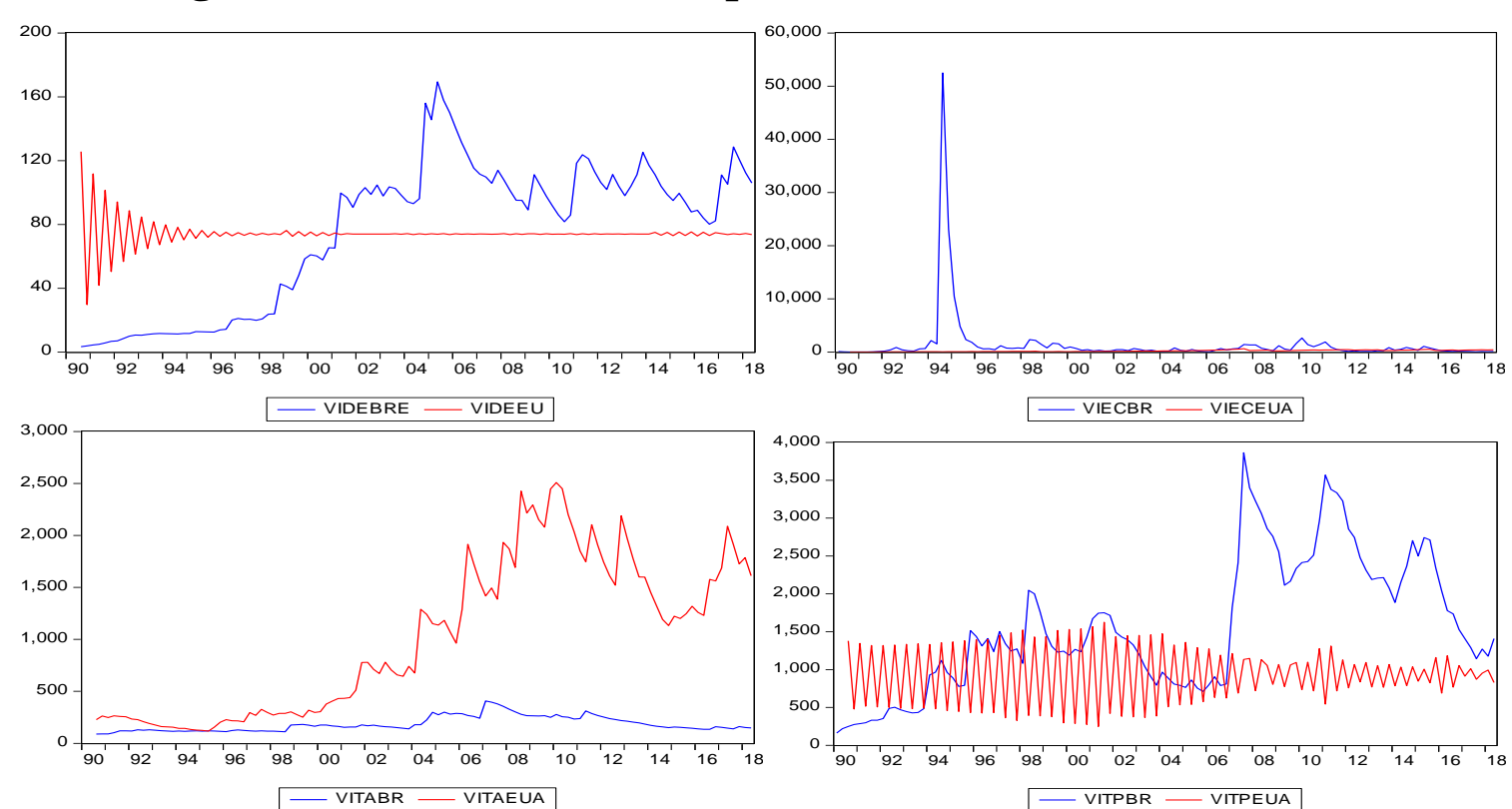

Nota: Primeiro gráfico da esquerda para direita: volatilidade da entrada de IDE no Brasil (VIDEBRE), volatilidade da entrada de IEC nos EUA (VIDEEU), volatilidade da entrada de IEC no Brasil (VECBR), volatilidade na entrada de IEC nos EUA (VIECEUA), volatilidade da saída de capitais do Brasil (VITABR), volatilidade da saída de capitais dos EUA (VITAEUA), volatilidade da entrada de capitais totais para o Brasil (VITPBR), e volatilidade da entrada de capitais totais para os EUA (VITPEUA).

Fonte: Resultado da pesquisa, variância produzida pelo modelo ARIMA $(1,10)$, elaboração própria, fonte dos dados: FMI, Estatísticas Financeiras Internacionais.

Comparando os níveis de volatilidade entre os países e por categorias de capitais, os gráficos sugerem que a entrada de capitais de IDE, IEC e ITP como proporção do PIB apresentou maior volatilidade para a economia brasileira do que essas entradas de capitais para os EUA. Em contraste, os gráficos também sugerem que o ITA/PIB é mais volátil para os EUA. Em especial, as estimativas de volatilidade do IDE para o Brasil exibem uma tendência ascendente clara antes da crise de 2008 e uma tendência descendente depois. Pode ser destacado o comportamento da volatilidade dos capitais externos desde a crise financeira dos subprimes. A volatilidade tem sido propensa a ataques, pois aumenta durante períodos em que o cenário internacional enfrenta turbulências. Essas discrepâncias na volatilidade dos capitais em períodos de crises ou de desequilíbrio caracterizamse como grande desafio político, sobretudo para as economias emergentes, como a brasileira. Essas oscilações nos capitais externos podem provocar saídas substanciais de capitais ou mesmo Sudden Stops nos países (FMI, 2006). 


\section{Determinantes da volatilidade dos capitais externos para a economia brasileira e americana}

As equações do modelo foram estimadas pelo modelo VEC, e, como as variáveis explicativas podem apresentar simultaneidade, para maior robustez da análise, as equações do modelo também foram estimadas pelo modelo DOLS.

Os modelos VAR analisam duas ou mais séries temporais de forma conjunta, com o objetivo de captar a dinâmica temporal de cada uma e a dinâmica entre elas. Essa metodologia engloba uma representação multiequacional na qual há uma equação para cada variável, e essa equação é composta por valores defasados da variável e dos valores defasados de outras variáveis do sistema. Ao considerar que as séries possam ser não estacionárias, mas cointegradas, insere-se a metodologia VEC, que consiste num VAR com restrições de cointegração entre as variáveis que possuem dinâmica de curto prazo e ajuste para o equilíbrio, como demonstrado na equação a seguir:

$$
\Delta W_{t}=\Pi W_{t-1}+\sum_{i=1}^{k-1} \Gamma_{i} \Delta W_{t-i}+u_{t}
$$

Da equação (5), o erro $u_{\mathrm{t}} \sim$ iid $\mathrm{N}(0, \psi), W_{t}$ corresponde ao vetor de variáveis endógenas do sistema, a parte de curto prazo dos parâmetros é representado por $\Gamma_{i}$ e a parte de longo prazo que contém as relações de cointegração corresponde a $\Pi W_{t-1}$ (LUTKEPOHL, 2005). Os vetores das variáveis endógenas dos determinantes da volatilidade dos capitais externos a serem estimadas são apresentados a seguir:

1) Relação 01 (Determinantes da volatilidade do IDE): $\mathrm{W}_{\mathrm{t}}=($ pibpercapitat, $e_{t}$, taxa de juros, inflação, ${ }_{t}$, preço do petróleo ${ }_{t}$, riscoglobal $\left._{t}\right)$;

2) Relação 02 (Determinantes da volatilidade do IEC): $\mathrm{W}_{\mathrm{t}}=($ pibpercapitat, $\mathrm{e}_{\mathrm{t}}$, taxa de jurost, inflaçãot, preço do petróleo $\mathrm{t}$, riscoglobal $\mathrm{t}$ );

3) Relação 03 (Determinantes da volatilidade do ITP): $\mathrm{W}_{\mathrm{t}}=($ pibpercapitat, $e_{t}$, taxa de jurost, inflação, , preço do petróleo, riscoglobal ${ }_{t}$ );

4) Relação 04 (Determinantes da volatilidade do ITA): $\mathrm{W}_{\mathrm{t}}=($ pibpercapitat, $e_{t}$, taxa de jurost, inflação, , preço do petróleo, riscoglobal ${ }_{t}$ ). 
A seleção do modelo VEC se embasou em alguns passos listados a seguir. Inicialmente foi selecionado o número de defasagens para cada relação econômica com base no modelo VAR e, posteriormente, o número de relações de cointegração.

i) Passo 1: O número das defasagens usadas nas estimações dos modelos foi selecionado de acordo com os critérios de informação (Akaike Information Criterion (AIC), Schwarz Bayesian Criterion (SBIC), Hanna Quinn (HQIC)) e a estatística LR (Likelihood Ratio).

ii) Passo 2: O número de vetores de cointegração foi definido com base no teste de posto de Johansen (1995). Esse teste engloba a utilização das estatísticas do traço e da raiz, característica máxima (ao nível de 5\% de significância). Todas as estimações incluíram uma constante irrestrita.

iii) Passo 3: Os modelos VEC foram estimados e testados para presença de correlação serial de segunda ordem nos resíduos (ao nível de 2,5\% de significância) e estabilidade (ausência de autovalores superiores a unidade).

Para (i) e (ii), a ordem das etapas para a escolha do melhor modelo seguiu a especificação de Lutkepohl (2005).

Como teste de robustez, será usado o modelo DOLS. A metodologia de Mínimos Quadrados Ordinários Dinâmicos (DOLS) foi desenvolvida por Stock e Watson (1993). Essa metodologia se aplica a séries cointegradas e permite a obtenção de estimadores robustos em pequenas amostras. Além disso, consiste numa técnica que permite a obtenção de estimadores eficientes para os vetores de cointegração que incluem os componentes determinísticos e acomoda de forma distinta variáveis de alta ordem de integração, além da possível simultaneidade entre as variáveis.

Na presença de variáveis não estacionárias, regressa-se uma variável em um nível contemporâneo na outra variável e nos lags e leads da sua primeira diferença, além do termo da constante. A presença desses lags e leads de diferentes variáveis na equação estimada, a qual possui um vetor cointegrante, elimina o viés de simultaneidade e de pequena amostra (STOCK; WATSON, 1993). O estimador obtido pelo DOLS tem um mecanismo que permite a correção da autocorrelação e endogeneidade e, para grandes amostras, equivale ao estimador de Máxima Verossimilhança (CHOI; OH, 2003).

As equações a seguir descrevem os determinantes da volatilidade dos capitais externos que foram estimados pelo modelo DOLS: 


$$
\begin{aligned}
& V_{I D E_{t}}=X_{t} M^{\prime}{ }_{t}+\sum_{i-m}^{i-m} \emptyset_{i} \Delta P I B C_{t-i}+\sum_{i-n}^{i-n} \rho_{i} \Delta I N f_{t-i}+\sum_{i-l}^{i-l} \emptyset_{i} \Delta T x J_{t-i}+ \\
& \sum_{i-p}^{i-p} \theta_{i} \Delta P P_{t-i}+\sum_{i-s}^{i-s} \propto_{i} \Delta R G_{t-i} \\
& \quad V I E C_{t}=X_{t} M^{\prime}{ }_{t}+\sum_{i-m}^{i-m} \emptyset_{i} \Delta P I B C_{t-i}+\sum_{i-n}^{i-n} \rho_{i} \Delta I N f_{t-i}+\sum_{i-l}^{i-l} \emptyset_{i} \Delta T x J_{t-i}+ \\
& \sum_{i-p}^{i-p} \theta_{i} \Delta P P_{t-i}+\sum_{i-s}^{i-s} \propto_{i} \Delta R G_{t-i} \\
& V_{I T P_{t}}=X_{t} M^{\prime}{ }_{t}+\sum_{i-m}^{i-m} \emptyset_{i} \Delta P I B C_{t-i}+\sum_{i-n}^{i-n} \rho_{i} \Delta I N f_{t-i}+\sum_{i-l}^{i-l} \emptyset_{i} \Delta T x J_{t-i}+ \\
& \sum_{i-p}^{i-p} \theta_{i} \Delta P P_{t-i}+\sum_{i-s}^{i-s} \propto_{i} \Delta R G_{t-i} \\
& \operatorname{VITA}_{t}=X_{t} M^{\prime}{ }_{t}+\sum_{i-m}^{i-m} \emptyset_{i} \Delta P I B C_{t-i}+\sum_{i-n}^{i-n} \rho_{i} \Delta I N f_{t-i}+\sum_{i-l}^{i-l} \emptyset_{i} \Delta T x J_{t-i}+ \\
& \sum_{i-p}^{i-p} \theta_{i} \Delta P P_{t-i}+\sum_{i-s}^{i-s} \propto_{i} \Delta R G_{t-i}
\end{aligned}
$$

As equações (6) a (9) foram estimadas para o Brasil e para os EUA de forma isolada. As variáveis dependentes de cada equação correspondem a VIDE (volatilidade da entrada de IDE), VIEC (volatilidade da entrada de IEC), VIT (volatilidade da entrada dos capitais totais do passivo, considerando a soma da entrada de IDE+IEC+OI), e VITA (volatilidade da saída de capitais totais, considerando a soma da saída de IDE+IEC+OI). Todos esses capitais externos foram ponderados pelo PIB de cada país correspondente.

Sobre as variáveis explicativas das equações estimadas, os fatores domésticos considerados foram o PIB per capita (PIBC), a inflação (inf) e a taxa de juros (TxJ). Essas variáveis são da própria economia. Isso significa que, quando a equação estimada foi a do Brasil, esses fatores domésticos correspondem aos da economia brasileira, o mesmo se aplica às equações estimadas dos EUA. Os fatores globais, que são comuns nas equações estimadas tanto para a economia brasileira quanto para a americana, correspondem ao preço do petróleo (PP) e ao risco global (RG).

Das equações (5) a (8), $\mathrm{M}=[c, \alpha, \beta, y, \lambda], \mathrm{X}=[1, \mathrm{PIB}$, inflo, txJ, PP, RG] e m, n, 1, p e s são os leads e (-m), (-n), (-1), (-p) e (-s) são os lags dos regressores. A estimação dos vetores cointegrantes pelo modelo DOLS permite obter estimadores mais robustos para pequenas amostras.

\section{Fonte de dados}

Este artigo fez uso das seguintes variáveis para analisar os determinantes da volatilidade dos capitais externos: investimento direto estrangeiro, expresso em milhões de dólares americanos (US\$ milhões), investimento em carteira (US\$ 
milhões) e outros investimentos (US\$ milhões). Essas séries foram obtidas do Fundo Monetário Internacional (FMI).

O risco global VIX Index S\&P 500 foi retirado do Chicago Board Options Exchange. O índice de preço do consumidor, expresso em unidades, com ano-base de 2010, e a taxa de juros (unidade) foram retirados do Fundo Monetário Internacional (FMI). Usou-se o PIB per capita do Brasil (US\$) disponível no World Economic Outlook do FMI. O preço do petróleo (US\$ per barrel) e o PIB per capita dos EUA (US\$) foram retirados do Federal Reserve Bank of St. Louis.

Todas as séries mencionadas foram logaritmizadas. As séries monetárias estão mensuradas a preços constantes, tendo 2012 como ano-base. A maior parte das variáveis foi retirada na frequência trimestral do primeiro trimestre de 1990 ao segundo trimestre de 2018. Os dados de risco global e do preço do petróleo estavam na frequência mensal e foram transformados na frequência trimestral.

\section{Resultados e discussões}

A globalização financeira surgiu como um movimento na economia mundial no decorrer dos anos. Entre diversos fatores, a diferença das taxas de juros entre os países no início dos anos 1960 motivou o investimento internacional (HELLEINER, 1994). Posteriormente, além do retorno, os investidores passaram a se preocupar com o risco, o que resultou no início da adoção de estratégias de diversificação dos portfólios. No final dos anos 1980, os fluxos de capitais brutos internacionais totalizavam aproximadamente US\$ 600 bilhões (HELLEINER, 1994). Nos anos 1990 verificou-se uma maior circulação dos capitais externos para as economias emergentes. Durante esse período, o fluxo de capitais externos apresentou dinâmicas distintas. Na Figura 2, tem-se a evolução dos capitais externos para o Brasil e os Estados Unidos. 


\section{Figura 2 - Evolução dos capitais externos no Brasil e nos EUA (US\$ milhões)}

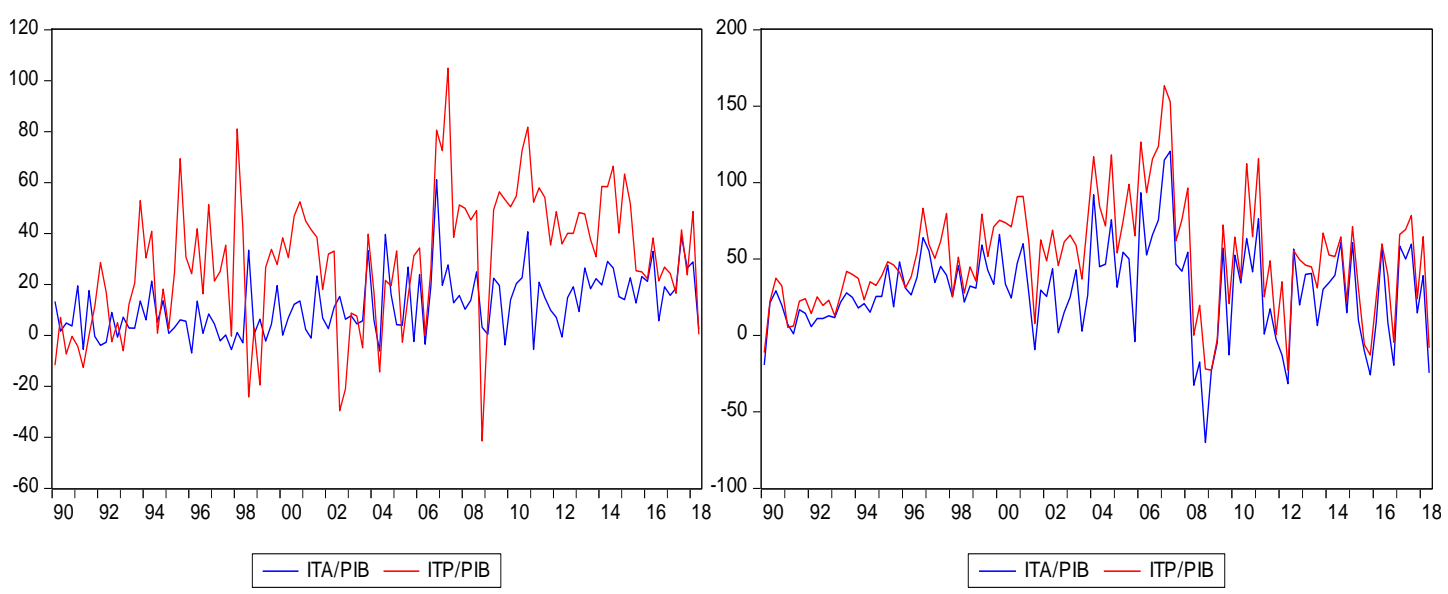

Nota: O gráfico da esquerda corresponde ao caso brasileiro, o lado direito, ao caso dos EUA. Entrada total de capitais externos como proporção do PIB (ITP/PIB), saída total de capitais externos (ITA/PIB).

Fonte: Elaboração própria, dados retirados do IFS/FMI.

A Figura 2 ilustra que as entradas brutas de capitais internacionais sofreram consideráveis acréscimos dos anos 1990 até a primeira metade dos anos 2000. Após a crise dos subprimes, no ano de 2008, as entradas de capitais mostraram quedas de forma acentuada, e recuperaram sua característica ascendente em torno do ano de 2009. Outro destaque do período foi a queda observada na entrada de capitais no final do ano de 2011, o qual foi marcado pela intensificação da crise da dívida soberana enfrentada pela Zona do Euro.

A composição da entrada de capitais apresenta heterogeneidade e, por isso, analisar a composição de distintos capitais auxilia na melhor compreensão do cenário que envolve as condições financeiras das economias. $\mathrm{O}$ investimento direto estrangeiro fornece um meio para criar ligações estáveis e duradouras entre os países, incentiva a transferência de tecnologia e know-how entre os países. O investimento em carteira pode ser definido como transações e posições realizadas por meio de títulos da dívida ou de capital, em geral, são mais atraídos pelo diferencial da taxa de juros. Alguns estudos, inclusive, indicam que os países atraírem uma parcela maior dos fluxos de capitais de longo prazo comparados aos de curto prazo auxilia a reduzir o risco de uma crise financeira (FRANKEL; ROSE, 1996).

$\mathrm{O}$ investimento direto estrangeiro possui uma natureza mais permanente dentro do país receptor comparado ao investimento em carteira (LINPSEY, 1999). Por sua vez, o investimento em carteira é conhecido como "hot Money". O 
investimento em carteira é conhecido por ter natureza mais volátil, e, por desafiar a política monetária ao afetar variáveis macroeconômica, ganha mais atenção dos reguladores, formuladores de políticas e investidores. O maior interesse das economias em desenvolvimento, como o Brasil, consiste em aumentar o capital estrangeiro com a finalidade de melhorar o desenvolvimento econômico (BROTO, DIAZ-CASSOU; ERCE, 2011). A evolução da entrada desses tipos de capitais isolados pode ser observada na Figura 3 a seguir.

\section{Figura 3 - Evolução na entrada de IDE e IEC no Brasil e nos Estados Unidos, (US\$ milhões)}

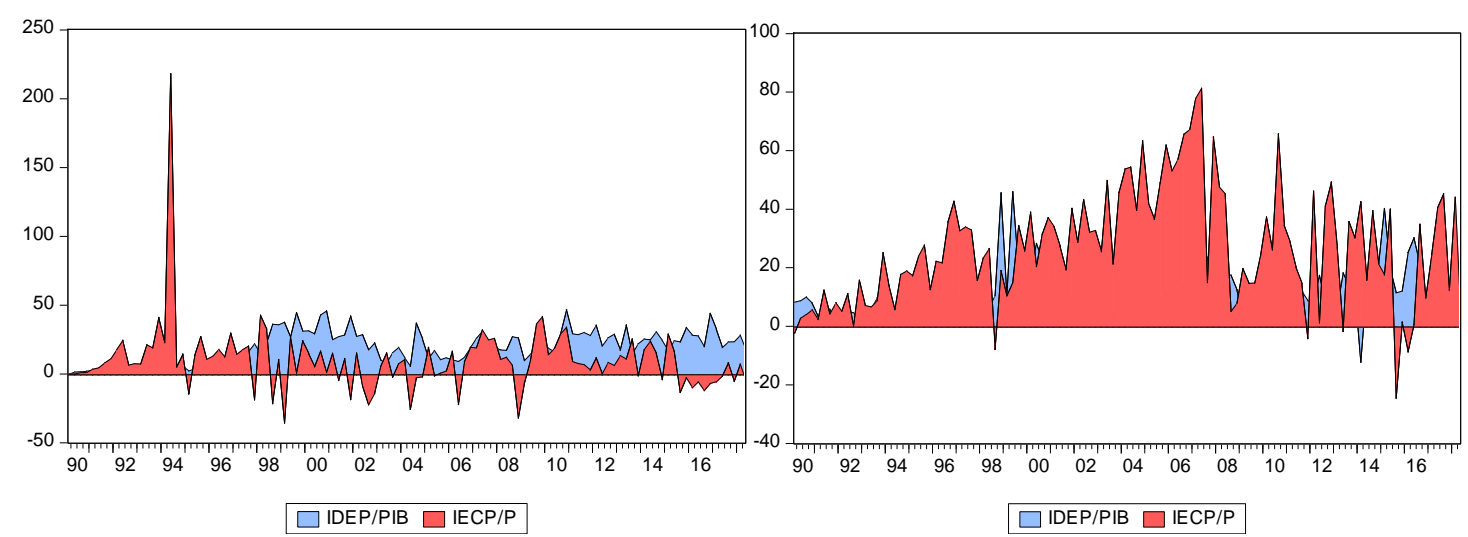

Nota: O gráfico da esquerda corresponde ao caso brasileiro, o lado direito, ao caso dos EUA. IDEP/PIB (entrada de IDE dividido pelo PIB), IECP/PIB (entrada de IEC em razão do PIB).

Fonte: Elaboração própria, dados retirados do IFS/FMI.

A Figura 3 ilustra a evolução das entradas brutas de capitais para os EUA e Brasil. Para as duas economias, é nítido a diferença em torno de montante e concentração da natureza de capitais externos. Para o caso brasileiro, nos anos 1990, era mais recorrente a participação do investimento em carteira. Ao longo do ano de 1998, a parcela de investimento direto estrangeiro passou a desempenhar um papel mais relevante. De fato, a economia brasileira é considerada a maior receptora de investimento direto estrangeiro da América Latina. No caso dos EUA, a Figura 3 ilustra o papel de destaque da entrada de investimento em carteira comparado ao investimento direto estrangeiro.

Ainda, o aumento e o colapso das entradas de capitais durante a crise dos subprimes estão mais ligados aos investimentos em carteira, com destaque para uma queda mais acentuada na economia brasileira. Assim, dadas as características das 
séries IEC e IDE, seria natural supor resultados distintos ao estimar a volatilidade por diferentes categorias, dado que algumas podem ser caracterizadas como mais voláteis.

O processo de análise foi iniciado pelo teste de estacionariedade das séries temporais em estudo. Os testes de raízes unitárias foram realizados com o objetivo de verificar a estacionariedade em nível. Para essa finalidade, usou-se os testes de ADF (DICKEY; FULLER, 1979), o Dickey Fuller (DF-GLS) e o de Phillips e Perron (1988). Com base nos Apêndices C, D, E e F, é possível inferir que todas as séries de dados são estacionárias em primeira diferença (ausência de séries I (2)), mas não em nível. Dessa maneira, prosseguiu-se com a estimação por meio dos modelos DOLS e VEC.

As estatísticas dos testes de autocorrelação serial (multiplicador de lagrange - LM) e os resultados dos testes de normalidade dos resíduos Jarque Berra (1980) podem ser vistos no Apêndice G. Todos os modelos atenderam ao pressuposto de inexistência de autocorrelação. $\mathrm{O}$ excesso de curtose foi o principal motivo que determinou a ausência de normalidade em alguns modelos. A ausência de normalidade residual não afeta seriamente os resultados nos modelos VEC, especialmente nos casos em que se observa que foi motivado por excesso de curtose (JUSCELIUS, 2006; JOHANSEN; NIELSEN, 2012).

A análise de cointegração por meio do modelo VEC é robusta à presença de heteroscedasticidade condicional e ao excesso de curtose (GONZALO, 1994). Os coeficientes obtidos por meio do modelo DOLS são robustos à presença de autocorrelação e heteroscedasticidade. Nas estimativas do modelo DOLS, foram usadas a matriz de Newey-West na geração dos erros padrões dos estimadores. Ainda, os resultados do apêndice $H$ sugerem que, pelo resultado do teste de cointegração baseado nos resíduos das estimações do modelo DOLS, todos os resíduos são estacionários.

Atendidos os passos dos modelos usados, para entender os determinantes da volatilidade dos capitais externos no Brasil e nos EUA do primeiro trimestre de 1990 ao segundo trimestre de 2018, construiu-se algumas regressões de séries temporais, nas quais as variáveis dependentes correspondem à volatilidade calculada pelos métodos citados anteriormente. As variáveis independentes compreendem um grupo de fatores domésticos e externos às duas economias. As variáveis estão em log. Os resultados estimados pelos modelos DOLS e VEC apresentaram diferenças em termos de sinais e significância estatística para alguns fatores. Por isso, a discussão dos resultados concentra-se nos fatores que foram 
iguais em termos de sinais e significância estatística para os dois modelos. $\mathrm{Na}$ Tabela 1, tem-se os resultados para os EUA.

Tabela 1 - Resultados dos determinantes da volatilidade dos capitais externos - EUA

\begin{tabular}{|c|c|c|c|c|}
\hline & \multicolumn{4}{|c|}{ VEC } \\
\hline & VAITPP & VAIDEPP & VAIECPP & VAITA \\
\hline \multicolumn{5}{|l|}{$\begin{array}{l}\text { Fatores } \\
\text { domésticos }\end{array}$} \\
\hline PIB per capita & $-7.734^{\#}$ & $25.525 * *$ & $-3.606^{\#}$ & $-1.068^{\#}$ \\
\hline Inflação & $10.822 * *$ & $-6.985^{\#}$ & $5.030 *$ & $8.199 * *$ \\
\hline Taxa de juros & $-0.185^{\#}$ & $-0.788 * *$ & $0.337 * *$ & $0.186^{\#}$ \\
\hline \multicolumn{5}{|l|}{ Fatores externos } \\
\hline Preço do Petróleo & $-1.423 * *$ & $-3.880 * * *$ & $1.251 * * *$ & $0.632 * *$ \\
\hline Risco global & $0,846^{* *}$ & $-2.600 * * *$ & $0.703 * * *$ & $0.652 * *$ \\
\hline \multirow[t]{2}{*}{ Constante } & 43.707 & -216.10 & 14.890 & 6.139 \\
\hline & \multicolumn{4}{|c|}{ DOLS } \\
\hline \multicolumn{5}{|l|}{$\begin{array}{l}\text { Fatores } \\
\text { domésticos }\end{array}$} \\
\hline PIB per capita & $-1.398246^{* *}$ & $3.109^{\#}$ & $0.993^{\#}$ & $8.096 * *$ \\
\hline Inflação & $0.595370^{\#}$ & $4.516^{\#}$ & $3.594^{\#}$ & $0.203^{\#}$ \\
\hline Taxa de juros & $0.008269^{\#}$ & $0.197^{\#}$ & $0.119^{\#}$ & $-0.053^{\#}$ \\
\hline \multicolumn{5}{|l|}{ Fatores externos } \\
\hline Preço do Petróleo & $0.195987 * *$ & $-0.922 * * *$ & $0.351^{\#}$ & $0.943 * * *$ \\
\hline Risco global & $-0.020133^{\#}$ & $0.536^{\#}$ & $-0.164^{\#}$ & $0.331^{\#}$ \\
\hline Constante & $18.55552 * *$ & $-46.686^{\#}$ & $-22.378^{\#}$ & $-69.145 * * *$ \\
\hline $\mathrm{R} 2$ & 0.23 & 0.60 & 0.93 & 0.97 \\
\hline
\end{tabular}

Nota: *** significativo a $1 \%$; ** significativo a $5 \%$; * significativo a $10 \%$; e \# não significativo. VAITPP (volatilidade da entrada de investimento total), VAIDEPP (volatilidade da entrada de investimento direto estrangeiro), VAIECPP (volatilidade da entrada de investimento em carteira), VAITA (volatilidade da saída total de capitais).

Fonte: Resultado da pesquisa, elaboração própria.

Os resultados, no geral, sugerem que as variáveis com maior frequência para explicar a volatilidade na entrada dos capitais externos nos EUA foram o risco global e o preço do petróleo. A volatilidade dos capitais externos pode ser acrescida diante de pequenas más notícias do cenário internacional, aqui mostrada por meio do risco global, mesmo que não seja observada uma mudança fundamental nos principais indicadores econômicos (FITZGERALD, 2001). Para as rubricas isoladas, o PIB per capita foi o principal condicionante da volatilidade na entrada de investimento direto estrangeiro nos EUA. Os principais mitigadores da volatilidade da entrada de IDE nos EUA foram o preço do petróleo e o risco global. 
No caso da volatilidade na entrada de investimento em carteira, os resultados apontaram três principais condicionantes, que foram a inflação, a taxa de juros e o preço do petróleo. Acréscimo de $1 \%$ da inflação, da taxa de juros e do preço do petróleo elevou a volatilidade na entrada de IEC nos EUA, cerca de $5,03 \%, 0,33 \%$ e $1,25 \%$, nessa ordem. Como sustentado por Davis e Van Wincoop (2018), um retorno esperado mais alto nos Estados Unidos pode induzir tanto os investidores dos EUA quanto os investidores externos a mudar sua carteira para os EUA. Esse movimento leva à maior entrada de capitais externos nos EUA, e menores saídas de capitais externos dos EUA.

Com relação à volatilidade da saída de capitais, os principais condicionantes da sua ocorrência foram o preço do petróleo, a inflação e o risco global. Um efeito do choque positivo do preço do petróleo, segundo Pagliari e Hannah (2017), pode ser visto no aumento do investimento bancário para os países, e, por meio disso, as instituições financeiras reinvestem seu aumento de receita no mercado financeiro, visando aumentar a diversificação dos seus investimentos. O resultado seria um aumento da volatilidade da saída de capitais das economias como resposta de um aumento do preço do petróleo (PAGLIARI; HANNAH, 2017).

Comparando os determinantes da volatilidade da entrada de investimento direto estrangeiro e investimento em carteira, os resultados sugerem que os fatores são totalmente distintos entre si. Alguma semelhança foi vista para os fatores que determinam a volatilidade da entrada de capitais e saída de capitais dos EUA. No caso, os fatores em comum para explicar essas volatilidades foram o preço do petróleo e o risco global.

A seguir, na Tabela 2, tem-se os resultados dos determinantes da volatilidade dos capitais externos para a economia brasileira. 
Tabela 2 - Determinantes da volatilidade dos capitais externos - Brasil

\begin{tabular}{|c|c|c|c|c|}
\hline & \multicolumn{4}{|c|}{ VEC } \\
\hline & VAITPP & VAIDEPP & VAIECPP & VAITA \\
\hline \multicolumn{5}{|l|}{$\begin{array}{l}\text { Fatores } \\
\text { domésticos }\end{array}$} \\
\hline PIB per capita & $0.528 * * *$ & $-1.973 * * *$ & $0.718^{\#}$ & $0.447^{\#}$ \\
\hline Inflação & $0.146 * * *$ & $0.707 * * *$ & $1.104 * * *$ & $-2.572 * * *$ \\
\hline Taxa de juros & $-0.457 * *$ & $0.259^{\#}$ & $5.330 * * *$ & $-13.571 * * *$ \\
\hline \multicolumn{5}{|l|}{ Fatores externos } \\
\hline Preço do Petróleo & $-0.260^{\#}$ & $2.249 * * *$ & $2.390 * *$ & $-9.029 * * *$ \\
\hline Risco global & $0.767 * * *$ & $0.364^{\#}$ & $2.545 * * *$ & $-2.143^{\#}$ \\
\hline \multirow[t]{2}{*}{ Constante } & 2.788 & 7.427 & -34.897 & 91.13 \\
\hline & \multicolumn{4}{|c|}{ DOLS } \\
\hline \multicolumn{5}{|l|}{$\begin{array}{l}\text { Fatores } \\
\text { domésticos }\end{array}$} \\
\hline PIB per capita & $0.606 * *$ & $-1.309 * * *$ & $1.143^{\#}$ & $-0.386 * *$ \\
\hline Inflação & $0.143 * * *$ & $0.212 * * *$ & $0.556^{* *} *$ & $0.061 * *$ \\
\hline Taxa de juros & $0.113^{\#}$ & $-0.633 * *$ & $2.536 * *$ & $0.279^{\#}$ \\
\hline \multicolumn{5}{|l|}{ Fatores externos } \\
\hline Preço do Petróleo & $0.069^{\#}$ & $1.204 * * *$ & $0.103^{\#}$ & $0.817 * * *$ \\
\hline Risco global & $0.714 * *$ & $-0.123^{\#}$ & $1.386^{*}$ & $0.240^{\#}$ \\
\hline Constante & $-0.371^{\#}$ & $10.547 * * *$ & $-15.996^{\#}$ & $3.246 * * *$ \\
\hline $\mathrm{R} 2$ & 0.87 & 0.95 & 0.66 & 0.77 \\
\hline
\end{tabular}

Os resultados da Tabela 2 mostram que os principais condicionantes da volatilidade da entrada de capitais externos no Brasil foram o PIB per capita, a inflação e o risco global.

Ao analisar para as diferentes categorias de capitais externos, os principais condicionantes da volatilidade da entrada de investimento em carteira no Brasil foram a inflação, a taxa de juros e o risco global. Aumento de $1 \%$ da inflação, da taxa de juros e do risco global fomentam a volatilidade da entrada de IEC no Brasil em cerca de $1,10 \%, 5,33 \%$ e $2,54 \%$, respectivamente.

Em especial, a elevação da inflação de determinado país significa maior retorno dos investimentos em carteira para investidores externos, e, por isso, estimula-os a investir no país anfitrião. Se há numa economia uma tendência 
crescente da inflação, isso gera volatilidade ao investimento em carteira (WAQAS; HASHMI; NAZIR, 2015).

Dos determinantes da volatilidade da entrada de IEC, pode ser destacado a magnitude do efeito da taxa de juros. Essa modalidade de capitais, geralmente, tem sua circulação alterada por diferenciais de juros doméstico e externo, o que justifica esse resultado. Modalidades de capitais como o IEC são totalmente apropriadas pela economia doméstica (ALBUQUERQUE, 2003).

Para a volatilidade na entrada de investimento direto estrangeiro, os principais condicionantes foram a inflação e o preço do petróleo. O papel da taxa de inflação para influenciar os fluxos de investimento direto estrangeiro no Brasil, no período de 1980 a 2004, também foi confirmada no estudo de Mattos, Cassuce e Campos (2007).

Diversos são os efeitos do preço do petróleo num país, por exemplo, desempenha papel no desenvolvimento econômico, estabilidade social e até mesmo na vida dos cidadãos (DING et al., 2017). Os resultados do presente estudo mostraram que um aumento do preço do petróleo pode provocar volatilidade na entrada de IDE. A explicação desse resultado pode ser pelo fato de o preço do petróleo influenciar o sentimento do investidor (DING et al., 2017).

Das variáveis, o PIB per capita foi considerado mitigador da volatilidade na entrada de IDE no Brasil. O aumento de $1 \%$ do PIB per capita reduziu a volatilidade da entrada de IDE em cerca de 1,97\%. Isso sinaliza que o aumento do crescimento doméstico brasileiro per capita pode diminuir a volatilidade de capitais considerados mais produtivos. Como sugerido por Dunning (2001), entradas de investimento direto estrangeiro em países em desenvolvimento, como o Brasil, visam à procura de mercado ou mesmo de recursos naturais. Além disso, entradas de IDE nos países em desenvolvimento como o Brasil precisam de alguns ativos intangíveis, tais como avanços tecnológicos, capital humano e demais, para maior uso desse financiamento (ALBUQUERQUE, 2003).

Em suma, os resultados sustentam que, para o Brasil e para os EUA, a inflação se mostrou um fator comum como condicionante da volatilidade na entrada de capitais totais e da saída de capitais totais. Para esse resultado, medidas internas tomadas pelos países auxiliam a eliminar a volatilidade da entrada de capitais externos. Por exemplo, para o controle dos níveis de inflação, a economia brasileira adota o sistema de metas de inflação desde 1999. 
Especificamente, para as categorias de capitais desagregados, os principais determinantes da volatilidade da entrada de investimento direto estrangeiro no Brasil e nos EUA foram distintos. Enquanto para os EUA o PIB per capita é um condicionante da volatilidade na entrada de IDE, no Brasil, os resultados apontaram o PIB per capita como um mitigador.

O crescimento do produto doméstico também se mostrou um fator consistente para explicar a volatilidade dos capitais externos no estudo de Koepke (2015). O resultado do presente estudo também sustenta os achados do FMI (2016), mostrando que os diferenciais de crescimento do PIB entre economias (avançadas e emergentes) desempenha um papel importante na circulação dos capitais externos.

Ainda analisando os determinantes da volatilidade na entrada de IDE nos EUA e no Brasil, os resultados revelaram que o preço do petróleo é um mitigador, e, para o Brasil, esse fator é um condicionante. Os EUA possuem uma quantidade considerável de demanda por petróleo, no ano de 2015, o país exportou 3,66 bilhões de toneladas de petróleo bruto (DING et al., 2017). Associar maior entrada de IDE com o preço do petróleo reflete o fato de que o aumento desse preço, em partes, indica as condições de demanda global e, consequentemente, maior renda global (PAGLIARI; HANNAH, 2017). Efeito que é mais acentuado se as economias são grandes exportadoras de petróleo, pois acréscimos da exportação promovem maior entrada de divisas na economia.

O investimento direto estrangeiro é caracterizado por uma modalidade de investimento de longo prazo, por isso, o desenvolvimento de turbulências globais, no estudo representado pelo risco global, possui menor efeito na circulação desse capital.

Por ser um capital mais produtivo, diversos estudos buscam analisar os determinantes do IDE. Alguns estudos foram inconclusivos a respeito dos fatores que determinam a circulação do IDE (ALBURQUERQUE et al., 2005; BRONER, VENTURA, 2016). A circulação do IDE possui maior ligação com estratégias das empresas multinacionais. Dessa forma, estratégias de investimentos decorrentes do IDE, segundo Dunning (2001), correspondem a um conjunto de combinação de vantagens da propriedade, localização e habilidade de formar parcerias com empresas locais.

Os principais resultados do presente estudo sustentam que os condicionantes da volatilidade de IEC no Brasil e nos EUA apresentam alguns 
fatores em comum, tais como a inflação, a taxa de juros e o preço do petróleo. Ao contrário dos determinantes do IDE que são mais concentrados nas características estruturais das economias, o IEC é mais determinado por diferencias de juros entre as economias.

No geral, o papel desempenhado pelos fatores globais, tais como preço do petróleo e risco global, segundo Broto, Diaz-Cassou e Erce (2011) evidencia que a volatilidade dos capitais externos é mais influenciada por fatores que não são do alcance das economias domésticas. De maneira semelhante, Fratzscher (2012) argumentou que os fatores externos se destacaram como responsáveis pela circulação dos fluxos de capitais durante o período da crise dos subprimes, e que os fatores domésticos dominaram a circulação dos capitais externos no período de 2009 e 2010, sobretudo para os fluxos que se destinaram às economias emergentes.

Ainda, como os resultados sustentam dois fatores externos como determinantes da volatilidade do capital externo, risco global e preço do petróleo, esses achados refletem os argumentos de Broto, Díaz-Cassou e Erce (2011). Para os autores, a relevância assumida pelos fatores globais como determinantes da volatilidade de diferentes tipos de capitais aponta-se como desafios dos formuladores de políticas das economias, a fim de tentar superar as dificuldades impostas pelos fluxos de capitais voláteis.

\section{Considerações finais}

Os fluxos mundiais de capitais externos aumentaram significativamente ao longo dos anos, e consequentemente aprofundou a volatilidade desses capitais. A volatilidade dos capitais externos consiste num risco para a estabilidade das economias e preenche uma pauta nas preocupações políticas das economias. $\mathrm{O}$ Brasil e os EUA não ficaram ausentes nesse processo, apresentando-se como receptores ou mesmo como financiadores externos das economias.

O presente estudo identifica volatilidade na entrada de capitais totais, de IDE e IEC, e para a saída de capitais totais. Comparando aos EUA, a economia brasileira possui maior volatilidade na entrada de IDE e IEC. Isso implica que os financiamentos da economia brasileira via IDE e IEC podem ser considerados incertos. Por outro lado, comparado ao Brasil, os Estados Unidos possuem maior 
volatilidade da saída de capitais totais. Isso reflete a vulnerabilidade da economia do Brasil como receptora de capitais externos, e a dos EUA, como financiadora.

O principal achado como condicionante da volatilidade da entrada total e da saída total de capitais externos das duas economias foi a inflação. Para esse fator em específico, as economias já possuem mecanismos. Por exemplo, o Brasil adota o sistema de metas de inflação desde o ano de 1999 para manter a inflação na meta esperada.

A volatilidade dos capitais externos também pode ser explicada por dois principais fatores externos, no caso, o preço do petróleo e o risco global. As economias do Brasil e dos EUA podem ser afetadas por ataques de turbulência financeira global. Por exemplo, no período analisado, a volatilidade dos capitais externos para as duas economias foi alterada no período da crise dos subprimes, e também nos períodos pré e pós-crise. Como esses principais fatores são externos às economias, sobretudo para o Brasil, esses achados dificultam sugestões de políticas, dado que consistem em forças que não estão ao alcance dos agentes domésticos.

$\mathrm{O}$ estudo conclui que os fatores que determinam a volatilidade devem ser analisados com cautela, dado que o efeito de um fator sobre determinada categoria de capital pode apresentar efeito contrário no outro. Logo, políticas ligadas à estabilidade financeira decorrentes de volatilidade de capitais devem-se pautar por quais tipos de capitais apresentam efeitos mais danosos em termos de volatilidade.

\section{Referências}

ALBUQUERQUE, R. The composition of international capital flows: risk sharing through foreign direct investment, Journal of International Economics, v. 61, n. 2, p. 353-383, 2003.

ALFARO, L.; KALEMLI-OZCAN, S.; VOLOSOVYCH, V. Capital flows in a globalized world: The role of policies and institutions 'Capital Controls and Capital Flows in Emerging Economies: Policies, Practices and Consequences'. Chicago: University of Chicago Press, p. 19-72, 2007.

BACEN - Banco Central do Brasil. Relatório de Estabilidade Financeira, v. 17, n. 2, 2018. 
BACEN - Banco Central do Brasil. Séries históricas. Disponível:<https://www4.bcb.gov.br/pec/series/port/metadados/mg184p.htm>. Data de acesso: 30/11/2019.

BRONER, F. A.; RIGOBON, R. Why are capital flows so much more volatile in emerging than in developed countries? Documentos de Trabajo (Banco Central de Chile), v. 328, n. 1, 2005.

BRONER, F.; DIDIER, T.; AITOR, E.; SCHMUKLER, S. L. Gross capital flows: dynamics and crises. Journal of Monetary Economics, v. 60, p. 113-133, 2013.

BRONER, F.; VENTURA, J. Rethinking the effects of financial globalization, The Quarterly Journal of Economics, v. 131, n. 3, p.1497-1542, 2016.

BROTO, C.; DÍAZ-CASSOU, J.; ERCE, A. Measuring and explaining the volatility of capital flows to emerging countries, Journal of Banking and Finance, v. 35, n. 8, p. 1941-1953, 2011.

CARVALHO, L. F.; VIEIRA, F. V.; RIBEIRO, K. C.; BORGES, W. G. Determinantes da volatilidade de investimentos estrangeiros no Brasil. Revista Base, v. 14, n. 2, p. 122-138, abr./jun. 2017.

CBOE. Chicago Board Options Exchange. Disponível em: < http://www.cboe.com /products/vix-index-volatility/vix-options-and-futures/vix-index/vix-historical-data . Data de acesso: 03/01/2019.

CHEUATHONGHUA, M.; PADUNGSAKSAWASDI, C. Do U.S. investors worry about fear in international equity markets? Empirical evidence on dynamic panel data. International Journal of Finance \& Economics, v. 24, n. 3, p. 1390-1403, 2019.

CHOI, W. G.; OH, S. A money demand function with output uncertainty, monetary uncertainty, and financial innovations. Journal of Money, Credit, and Banking, v. 35, n. 5 , p. $685-710,2003$.

DAVIS, J. S.; VAN WINCOOP, E. Globalization and the increasing correlation between capital inflows and outflows. Journal of Monetary Economics, v. 100, p. 83-100, 2018.

DING, Z.; LIU, Z.; ZHANG, Y.; LONG, R. The contagion effect of international crude oil price fluctuations on chinese stock Market investor sentiment. Applies Energy, v. 187, n. 1, p. 27-36, 2017. 
DOW, S. C. Money and the economic process. Cheltenham: Edward Elgar Publishing, 1993.

DUNNING, J. H. The key literature on IB activities: 1960-2000. In: RUGMAN, A.; BREWER, T. L. (Eds.). The Oxford Handbook of International Business. Oxford: Oxford University Press, 2001.

ENGLE, R. F.; RANGEL, J. G. The spline-GARCH model for low-frequency volatility and its global macroeconomic causes. Review of Financial Studies, v. 21, n. 3, p. 1187-1222, 2008.

FONSECA, M. R. R.; SILVA, P. P.; ARAÚJO, E. C. Política monetária e ciclo financeiro global: uma análise sobre o caso brasileiro durante o regime de metas de inflação. Brazilian Keynesian Review, v. 3, n. 2, p. 82-106, 2017.

FRANKEL, J. A.; ROSE, A. K. Currency crashes in emerging markets: an empirical treatment, Journal of International Economics, v. 41, n. 3-4, p. 351-366, 1996.

FRATZSCHER, M. Capital flows, push versus pull factors and the global financial crisis. Journal of International Economics, v. 88, n. 2, p. 341-356, 2012.

FED - Federal Reserve Bank of St. Louis. Disponível em:<https://fred.stl ouisfed.org/series/A939RX0Q048SBEA>. Data de acesso: 03/01/2019.

GOLDSTEIN, I.; RAZIN, A. An information-based tradeoff between foreign direct investment and foreign portfolio investment. Journal of International Economics, v. 70, n. 1, p. 271-295, 2006.

GONZALO, J. Five alternative methods of estimating long-run equilibrium relationships, Journal of Econometrics, v. 60, n. 1-2, p. 203-233, 1994.

HELLEINER, E. States and the reemergence of global finance. From Bretton Woods to the 1990s. Ithaca: Cornell University Press, 1994.

IFS - International Financial Statistics. Disponível em: https://www.imf.org/en/ Data>. Data de acesso: 03/01/2019.

IMF DATA. Disponível em: <http://data.imf.org/? sk=40313609-F037-48C1-84B1-E1F1CE54D6D5>. Data de acesso: 02/01/2019.

IMF - International Monetary Fund. External sector report-tackling global imbalances amid rising trade tensions. Washington, 2018. 
JOHANSEN, S.; NIELSEN, M. O. Likelihood inference for a fractionally cointegrated vector autoregressive model. Econometrica, v. 80, n. 6, p. 2667-2732, 2012.

JUSELIUS, K. The cointegrated VAR model-Methodology Applications. Oxford: Oxford University Press, 2006.

KOEPKE, R. What drives capital flows to emerging markets? a survey of the empirical literature. Technical report (62770). University Library of Munich, 2015.

LINPSEY, R. The role of foreign direct investment in international capital flows. Chicago: University of Chicago Press, p. 307-362, 1999.

LUTKEPOHL, H. Structural vector autoregresssive analysis for cointegrated variables. EUI Working Paper ECO, n. 2005/2, 2005.

MATTOS, L. B.; CASSUCE, F. C.; CAMPOS, A. C. Determinantes dos investimentos diretos estrangeiros no Brasil 1980-2004, Revista de Economia Contemporânea, v. 11, n. 1, p. 39-60, 2007.

MUNHOZ, V. C. V.; CORRÊA, V. P. Volatilidade dos fluxos financeiros no Brasil: Uma análise empírica por meio do modelo ARCH. Análise Econômica, n. 52, p. 201-232, 2009.

OBSTFELD, M. Financial flows, financial crises, and global imbalances. Journal of International Money and Finance, v. 31, n. 3, p. 469-480, 2012.

PAGLIARI, M. S.; HANNAN, S. A. The volatility of capital flows in emerging markets: measures and determinants. IMF Working Papers, 2017.

REY, H. Dilemma not trilemma: the global financial cycle and monetary policy independence. National Bureau of Economic Research, Working Paper, 21162, 2015.

ROCHA, K.; MOREIRA, A.; SILVEIRA, M. O fluxo de capital para as economias emergentes e o grau de desenvolvimento do sistema financeiro. Estudos Econômicos, v. 47, n. 2, 2017.

STOCK, J. H.; WATSON, M. W. A simple estimator of co-integrating vectors in higher order integrated systems. Econometrica, v. 61, n. 4, p. 783-820, 1993.

SULA, O.; WILLETT, T. D. The reversibility of different types of capital flow to emerging markets. Emerging Markets Review, v. 10, n. 4, p. 296-310, 2009. 
TESAR, L. L.; WERNER, I. M. US equity investment in emerging stock markets, The World Bank Economic Review, v. 9, n. 1, p. 109-129, 1995.

WAQAS, Y.; HASHMI, S. H.; NAZIR, M.I. Macroeconomic factors and foreign portfolio investment volatility: A case of South Asian countries. Future Business Journal, v. 1, n. 1-2, p. 65-74, 2015.

WEI, S. Domestic crony capitalism and international fickle capital: Is there a connection? International Finance, v. 4, n. 1, p. 15-45, 2001.

WEISS, M. A.; PRATES, D. M. Análise teórica e empírica dos determinantes dos fluxos de capitais financeiros para os países em desenvolvimento no contexto da globalização financeira. Nova Economia, v. 27, 2017.

WYPLOSZ, C. How risky is financial liberalization in the developing countries? Centre for Economic Policy Research Discussion Paper, 2724, 2001. 


\section{Apêndices}

Apêndice A - Identificação da volatilidade condicional para os capitais externos - EUA

\begin{tabular}{l|llll}
\hline & \multicolumn{1}{|c}{ IDEP } & \multicolumn{1}{c}{ IECP } & \multicolumn{1}{c}{ ITA } & \multicolumn{1}{c}{ ITP } \\
\hline Constante & $3.13 \mathrm{E}+09^{* *}$ & $1.53 \mathrm{E}+10^{* *}$ & $5.03 \mathrm{E}+09^{\#}$ & $4.91 \mathrm{E}+10^{* *}$ \\
Resíduo & $0.490957^{* *}$ & $0.420353^{\#}$ & $0.368311^{\#}$ & $0.462877^{\#}$ \\
GARCH (-1) & $0.001743^{\#}$ & $0.054837^{\#}$ & $0.548941^{* *}$ & $-0.007974^{\#}$ \\
& IDE/PIB & IEC/PIB & ITA/PIB & ITP/PIB \\
Constante & $18.29734^{\#}$ & $12.26439^{\#}$ & $-2.884800^{\#}$ & $106.2660^{\#}$ \\
Resíduo & $0.528221^{* *}$ & $0.205119^{\#}$ & $-0.044100^{\#}$ & $0.290023^{\#}$ \\
GARCH (-1) & $0.465576^{\#}$ & $0.806271^{* * *}$ & $1.072892^{* * *}$ & $0.701345^{* * *}$ \\
\hline
\end{tabular}

Fonte: FMI, Estatísticas Financeiras Internacionais, elaboração própria.

Apêndice B - Identificação da volatilidade condicional para os capitais externos - Brasil

\begin{tabular}{l|llll}
\hline & \multicolumn{1}{|c}{ IDEP } & \multicolumn{1}{c}{ IECP } & \multicolumn{1}{c}{ ITA } & \multicolumn{1}{c}{ ITP } \\
\hline Constante & $41512448^{* *}$ & $-4818.769^{\#}$ & $-71987.79^{\#}$ & $3.19 \mathrm{E}+08^{* *}$ \\
Resíduo & $0.974888^{* *}$ & $1.267818^{* * *}$ & $-0.067271^{\#}$ & $0.704125^{*}$ \\
GARCH (-1) & $-0.094502^{\#}$ & $0.441946^{* * *}$ & $1.113437^{* * *}$ & $-0.206588^{*}$ \\
& IDE/PIB & IEC/PIB & ITA/PIB & ITP/PIB \\
Constante & $1.600843^{\#}$ & $2.306790^{\#}$ & $-2.884800^{*}$ & $66.51937^{\#}$ \\
Resíduo & $0.393462^{* *}$ & $1.084268^{* * *}$ & $-0.044100^{\#}$ & $0.169956^{\#}$ \\
GARCH (-1) & $0.666275^{* * *}$ & $0.440460^{* * *}$ & $1.072892^{* * *}$ & $0.798009^{* * *}$ \\
\hline
\end{tabular}

Fonte: FMI, Estatísticas Financeiras Internacionais, elaboração própria.

\section{Apêndice C - Teste de Raiz Unitária em Nível para o Brasil ${ }^{3}$}

\begin{tabular}{llll}
\hline \multicolumn{1}{c}{ Variável } & \multicolumn{1}{c}{ ADF (8 lags) } & \multicolumn{1}{c}{ DFGLS (8 lags) } & \multicolumn{1}{c}{ PPerron } \\
\hline IDEP & $-0.593367(-)^{\#}$ & $-3.445556(\mathrm{~T})^{\#}$ & $-5.165393(\mathrm{~T})^{* * *}$ \\
IECP & $-7.381863(\mathrm{~T})^{* * *}$ & $-7.326672(\mathrm{~T})^{* * *}$ & $-7.69757(\mathrm{~T})^{* * *}$ \\
ITA & $-9.78413(\mathrm{~T})^{* * *}$ & $-5.241815(\mathrm{~T})^{* * *}$ & $-3.493227(\mathrm{C})^{* * * *}$ \\
ITP & $-4.565291(\mathrm{~T})^{* * *}$ & $-4.547411(\mathrm{~T})^{* * *}$ & $-4.56591(\mathrm{C})^{* * *}$ \\
Preço do petróleo & $-1.97537(\mathrm{C})^{\#}$ & $-1.539665(\mathrm{C})^{\#}$ & $-1.718182(\mathrm{C})^{\#}$ \\
Taxa de juros & $-42.0335(\mathrm{C})^{* * *}$ & $-1.542637(\mathrm{~T})^{\#}$ & $-27.09387(\mathrm{~T})^{* * *}$ \\
Risco global & $-4.005587(-)^{* * *}$ & $-3.989735(\mathrm{~T})^{* * *}$ & $-3.886318(\mathrm{C})^{* * *}$ \\
PIB per capita & $-1.463877(\mathrm{~T})^{\#}$ & $-1.446534(\mathrm{~T})^{\#}$ & $-1.061042(\mathrm{~T})^{* * *}$ \\
Inflação & $2.03055(-)^{*}$ & $-2.791605(\mathrm{~T})^{\#}$ & $4.197654(-)^{* * *}$ \\
Crise & $-2.829217(\mathrm{C})^{\#}$ & $-2.78652(\mathrm{C})^{* * *}$ & $-3.083734(\mathrm{~T})^{\#}$ \\
\hline
\end{tabular}

\footnotetext{
${ }^{3}$ Os testes ADF, DFGLS, e P. Perron consideram como hipótese nula a presença de raiz unitária. No teste KPSS a hipótese nula é a presença de estacionariedade. Os testes foram realizados com a presença somente do intercepto (I), com a presença do intercepto e do termo de tendência (T) e sem a presença de termos determinísticos (-).
} 


\begin{tabular}{llll}
\hline IDEP/PIB & $-2.464491(\mathrm{C})^{\#}$ & $-1.235248(\mathrm{C})^{\#}$ & $-5.233255(\mathrm{~T})^{* * *}$ \\
IECP/PIB & $-8.712595(\mathrm{~T})^{* * *}$ & $-5.335604(\mathrm{C})^{* * *}$ & $-9.747191(\mathrm{~T})^{* * * *}$ \\
ITA/PIB & $-9.420875(\mathrm{C})^{* * *}$ & $-9.439837(\mathrm{C})^{* * *}$ & $-10.14634(\mathrm{C})^{* * *}$ \\
ITP/PIB & $-6.268516(\mathrm{C})^{* * *}$ & $-6.191427(\mathrm{~T})^{* * *}$ & $-6.171681(\mathrm{C})^{* * *}$ \\
\hline
\end{tabular}

Nota: *** significativo a $1 \%$; ** significativo a $5 \%$; * significativo a $10 \%$; e \# não significativo. Fonte: Resultado da pesquisa, elaboração própria.

\section{Apêndice D - Teste de Raiz Unitária em Primeira diferença para o Brasil}

\begin{tabular}{llll}
\hline \multicolumn{1}{c}{ Variável } & \multicolumn{1}{c}{ ADF (8 lags) } & \multicolumn{1}{c}{ DFGLS (8 lags) } & \multicolumn{1}{c}{ PPerron } \\
\hline IDEP & $-11.2184(-)^{* * * *}$ & $-15.18726(\mathrm{~T})^{* * * *}$ & $-23.2088(\mathrm{C})^{* * * *}$ \\
IECP & $-10.99199(\mathrm{~T})^{* * * *}$ & $-16.77166(\mathrm{~T})^{* * *}$ & $-33.23254(-)^{* * * *}$ \\
ITA & $-8.913304(\mathrm{~T})^{* * *}$ & $-16.25572(\mathrm{~T})^{* * *}$ & $-8.961348(\mathrm{C})^{* * * *}$ \\
ITP & $-14.13722(\mathrm{~T})^{* * *}$ & $-12.31197(\mathrm{~T})^{* * *}$ & $-14.13722(\mathrm{C})^{* * *}$ \\
Preço do petróleo & $-10.29734(\mathrm{C})^{* * *}$ & $-9.682804(\mathrm{C})^{* * *}$ & $-11.05875(-)^{* * *}$ \\
Taxa de juros & $-42.0335(\mathrm{C})^{* * *}$ & $-2.06023(\mathrm{~T})^{\#}$ & $-163.96420(\mathrm{~T})^{* * * *}$ \\
Risco global & $-9.945367(\mathrm{C})^{* * *}$ & $-11.4983(\mathrm{~T})^{* * *}$ & $-13.99442(\mathrm{~T})^{* * * *}$ \\
PIB per capita & $-10.53408(\mathrm{~T})^{* * *}$ & $-10.61039(\mathrm{~T})^{* * *}$ & $-10.75390(\mathrm{~T})^{* * * *}$ \\
Inflação & $-3.832672(\mathrm{C})^{* * *}$ & $-3.647434(\mathrm{~T})^{* * *}$ & $-3.260009(-)^{* * *}$ \\
Crise & $-10.48809(\mathrm{C})^{* * * *}$ & $-10.53565(\mathrm{C})^{* * *}$ & $-10.44316(\mathrm{~T})^{* * *}$ \\
IDEP/PIB & $-9.59161(-)^{* * *}$ & $-11.43804(\mathrm{C})^{* * *}$ & $-19.6716(\mathrm{C})^{* * *}$ \\
IECP/PIB & $-8.712595(\mathrm{~T})^{* * *}$ & $-8.742736(\mathrm{C})^{* * *}$ & $-93.26263(\mathrm{C})^{* * * *}$ \\
ITA/PIB & $-9.313004(-)^{* * *}$ & $-1.284587(\mathrm{~T})^{\#}$ & $-62.61845(\mathrm{C})^{* * *}$ \\
ITP/PIB & $-8.75136(\mathrm{~T})^{* * *}$ & $-13.22237(\mathrm{~T})^{* * *}$ & $-58.25528(\mathrm{~T})^{* * *}$ \\
\hline
\end{tabular}

Nota: $* * *$ significativo a $1 \%$; ** significativo a $5 \%$; * significativo a $10 \%$; e \# não significativo. Fonte: Resultado da pesquisa, elaboração própria. 
Apêndice E - Teste de Raiz Unitária em Nível para os EUA

\begin{tabular}{llll}
\hline \multicolumn{1}{c}{ Variável } & \multicolumn{1}{c}{ ADF (8 lags) } & \multicolumn{1}{c}{ DFGLS (8 lags) } & \multicolumn{1}{c}{ PPerron } \\
\hline IDEP & $-4.176826(\mathrm{C})^{* * * *}$ & $-1.551599(\mathrm{C})^{\#}$ & $-3.046383(-)^{* * *}$ \\
IECP & $-3.538806(\mathrm{C})^{* * * *}$ & $-2.330986(\mathrm{C})^{\#}$ & $-7.064531(\mathrm{C})^{* * * *}$ \\
ITA & -7.062709()$^{* * * *}$ & $-4.436284(\mathrm{~T})^{* * *}$ & $-5.373939(-)^{* * *}$ \\
ITP & $-3.605431(\mathrm{C})^{* * *}$ & $-3.537786(\mathrm{C})^{\#}$ & $-3.440749(-)^{* * *}$ \\
Preço do petróleo & $-10.29734(\mathrm{C})^{* * *}$ & $-2.847160(\mathrm{~T})^{\#}$ & $-0.303288(-)^{\#}$ \\
Taxa de juros & $-4.128811(\mathrm{~T})^{* * *}$ & $-3.155215(\mathrm{C})^{\#}$ & $-2.819151(\mathrm{~T})^{\#}$ \\
Risco global & $-4.005587(\mathrm{C})^{* * * *}$ & $-3.873897(\mathrm{C})^{* * *}$ & $-1.055744(-)^{\#}$ \\
PIB per capita & $3.640339(-)^{* * *}$ & $-1.870488(\mathrm{~T})^{\#}$ & $-0.439597(\mathrm{C})^{\#}$ \\
Inflação & $5.164148(-)^{* * *}$ & $2.026853(\mathrm{C})^{\#}$ & $-0.3510211(\mathrm{C})^{\#}$ \\
Crise & $-2.829217(\mathrm{C})^{\#}$ & $-2.78652(\mathrm{C})^{* * *}$ & $-3.083734(\mathrm{~T})^{\#}$ \\
IDEP/PIB & $-.042042(\mathrm{~T})^{* * *}$ & $-4.505986(\mathrm{~T})^{* * *}$ & $-3.475045(-)^{* * *}$ \\
IECP/PIB & $-3.604976(\mathrm{C})^{* * *}$ & $-3.114523(\mathrm{~T})^{\#}$ & $-3.013564(-)^{\#}$ \\
ITA/PIB & $-4.662593(\mathrm{C})^{* * *}$ & $-3.686960(\mathrm{~T})^{* * *}$ & $-4.779255(-){ }^{* * *}$ \\
ITP/PIB & $-3.664709(\mathrm{C})^{* * * *}$ & $-2.909396(\mathrm{~T})^{\#}$ & $-6.30436(\mathrm{~T})^{* * * *}$ \\
\hline
\end{tabular}

Nota: *** significativo a $1 \%$; ** significativo a $5 \%$; $*$ significativo a $10 \%$; e \# não significativo.

Fonte: Resultado da pesquisa, elaboração própria.

\section{Apêndice F - Teste de Raiz Unitária em Primeira diferença para os EUA}

\begin{tabular}{llll}
\hline \multicolumn{1}{c}{ Variável } & \multicolumn{1}{c}{ ADF (8 lags) } & \multicolumn{1}{c}{ DFGLS (8 lags) } & \multicolumn{1}{c}{ PPerron } \\
\hline IDEP & $-9.335729(\mathrm{~T})^{* * *}$ & $-9.352115(\mathrm{C})^{* * * *}$ & $-39.62051(\mathrm{C})^{* * * *}$ \\
IECP & $-11.58226(\mathrm{C})^{* * * *}$ & $-11.40553(\mathrm{C})^{* * *}$ & $-28.15181(\mathrm{C})^{* * *}$ \\
ITA & $-16.79025(\mathrm{C})^{* * *}$ & $-15.58496(\mathrm{C})^{* * *}$ & $-18.05492(\mathrm{C})^{* * *}$ \\
ITP & $-17.848111(\mathrm{C})^{* * *}$ & $-17.30292(\mathrm{C})^{* * *}$ & $-17.92783(\mathrm{C})^{* * *}$ \\
Preço do petróleo & $-0,6777716(-)^{\# *}$ & $-9.682804(\mathrm{C})^{* * *}$ & $-11.08077(\mathrm{C})^{* * *}$ \\
Taxa de juros & $-4.476116(\mathrm{C})^{* * *}$ & $-4.465594(\mathrm{C})^{* * *}$ & $-7.225930(\mathrm{C})^{* * *}$ \\
Risco global & $-9.945367(\mathrm{C})^{* * *}$ & $-11.4983(\mathrm{~T})^{* * *}$ & $-14.03628(\mathrm{C})^{* * *}$ \\
PIB per capita & $-7.033674(\mathrm{C})^{* * *}$ & $-4.435238(\mathrm{C})^{* * *}$ & $-7.225930(\mathrm{C})^{* * *}$ \\
Inflação & $-12.07143(\mathrm{~T})^{* * *}$ & $-5.999430(\mathrm{C})^{* * *}$ & $-8.79297(\mathrm{C})^{* * *}$ \\
Crise & $-10.48809(\mathrm{C})^{* * *}$ & $-10.53565(\mathrm{C})^{* * *}$ & $-10.48809(\mathrm{C})^{* * *}$ \\
IDEP/PIB & $-8.598463(\mathrm{~T})^{* * *}$ & $-9.768309(\mathrm{~T})^{* * *}$ & $-64.69122(\mathrm{C})^{* * *}$ \\
IECP/PIB & $-11.60903(\mathrm{C})^{* * *}$ & $-11.38233(\mathrm{C})^{* * *}$ & $-25.36923(\mathrm{C})^{* * * *}$ \\
ITA/PIB & $-16.96080(\mathrm{C})^{* * *}$ & $-3.0873117(\mathrm{~T})^{\# *}$ & $-18.00837(\mathrm{C})^{* * *}$ \\
ITP/PIB & $-17.65653(\mathrm{C})^{* * *}$ & $-3.298373(\mathrm{~T})^{\#}$ & $-17.65653(\mathrm{C})^{* * *}$ \\
\hline
\end{tabular}

Nota: $* * *$ significativo a $1 \%$; $* *$ significativo a $5 \%$; $*$ significativo a $10 \%$; e \# não significativo.

Fonte: Resultado da pesquisa, elaboração própria. 
Apêndice G - Teste de autocorrelação e normalidade residual do modelo VEC (p-valor)

\begin{tabular}{|c|c|c|c|}
\hline \multicolumn{4}{|c|}{ Estados Unidos } \\
\hline \multirow{2}{*}{$\begin{array}{l}\text { Modelos de } \\
\text { volatilidade }\end{array}$} & \multicolumn{2}{|c|}{ Teste LM } & \multirow[t]{2}{*}{$\mathbf{J B}$} \\
\hline & Ordem1 & Ordem 2 & \\
\hline ITP & 0.27345 & 0.76092 & 0.00000 \\
\hline ITA & 0.54954 & 0.91058 & 0.00000 \\
\hline IDE & 0.53353 & 0.79799 & 0.43760 \\
\hline IEC & 0.30818 & 0.23821 & 0.00000 \\
\hline \multicolumn{4}{|c|}{ Brasil } \\
\hline ITP & 0.13168 & 0.25872 & 0.00000 \\
\hline ITA & 0.13532 & 0.37167 & 0.00000 \\
\hline IDE & 0.07536 & 0.41733 & 0.00000 \\
\hline IEC & 0.48031 & 0.26645 & 0.41458 \\
\hline
\end{tabular}

Fonte: Resultados da pesquisa, elaboração própria.

Apêndice H - Resultado do teste de cointegração dos resíduos - DOLS

\begin{tabular}{|c|c|c|c|}
\hline \multicolumn{4}{|c|}{ Estados Unidos } \\
\hline $\begin{array}{l}\text { Modelos de } \\
\text { volatilidade }\end{array}$ & $\begin{array}{c}\text { Teste de raiz } \\
\text { unitária do resíduo }\end{array}$ & Engle-Granger & $\begin{array}{l}\text { Phillips- } \\
\text { Oulivares }\end{array}$ \\
\hline ITP & $-39.972(\mathrm{~T})^{* * *}$ & $-2.57^{\#}$ & $-39.51 * *$ \\
\hline ITA & $-4.464(\mathrm{~T}) * * *$ & $-3.77^{\#}$ & $-3.83^{\#}$ \\
\hline IDE & $-4.092(\mathrm{~T}) * * *$ & $-4.48^{\#}$ & $-4.44^{\#}$ \\
\hline IEC & $-4.235(\mathrm{~T}) * * *$ & $-3.99^{\#}$ & $-4.06^{\#}$ \\
\hline \multicolumn{4}{|c|}{ Brasil } \\
\hline ITP & $-4.126(-)^{* * *}$ & $-33.92^{\#}$ & $-4.73 *$ \\
\hline ITA & $-4.571(-) * * *$ & $-28.46^{\#}$ & $-3.89^{\#}$ \\
\hline IDE & $-4.246(-) * * *$ & $-35.00 *$ & $-4.47^{\#}$ \\
\hline IEC & $-5.207(\mathrm{C}) * * *$ & $-39.66 * *$ & $-4.90 * *$ \\
\hline
\end{tabular}

Nota: *** significativo a $1 \%$; ** significativo a $5 \%$; $*$ significativo a $10 \%$; e \# não significativo.

Fonte: Resultado da pesquisa, elaboração própria. 